\title{
The Influential Factors on Internationalization of the SMEs in China: on Wenzhou's Shoe Industry and Policy Implications
}

\author{
Shouchao He \\ Wenzhou University \\ Chashan Town, High Education Campus, Wenzhou, China, 325035 \\ E-mail: wzuniversity@126.com
}

Received: January 10, $2011 \quad$ Accepted: February 4, $2010 \quad$ doi:10.5430/rwe.v2n1p48

This research is financed by Wenzhou Municipal Sci-tech Bureau, Project No.R20090067; and Oujiang college of Wenzhou university

\begin{abstract}
As a major center in the world's largest footwear producing and exporting country, China is trying to transform its labor intensive manufacturing industry into a more competitive and internationalized one. However, there are still many uncertainties in the process of internationalization. Wenzhou, one of the major industrial cities, is also facing this challenge. This paper first examine the key influential factors for internationalization of SMEs from a theoretical perspective, then plug the data and factors from Wenzhou into the framework to analyze the influential factors on the Internationalization of the SMEs in Wenzhou. Results demonstrate that both the external factors, like global financial crisis, and internal ones, like the local infrastructure, government support, are critical for the internationalization of Wenzhou SMEs. Policy implications are addressed to promote the internationalization of SMEs.
\end{abstract}

Keywords: SMEs, Internationalization, Shoemaking industry, Influential factors

\section{Introduction}

According to the Schumpeter's theory on destructive innovation, the SMEs (Small and medium sized enterprise) has an important role in the local economic chains of a country and the process of creative destruction. This paper will focus on discussing the factors that influence the internationalization of SMEs and product global diffusion, or we call it internationalization and globalization.

The widespread interest in the concept of "multinational firms", "globalization" and "internationalization" has given a rapid growth of many literatures and books on various aspects of the international factors and strategies of firms. There is tons of research on the internationalization of large corporations, particularly on the big ones originally from North America and Europe. However, we believe that most of the firms started international operations when they are still comparatively small (or we call them SMEs) and gradually develop their operations and business in other countries. From the previous literature studies of international business expansion, we can find clear observations indicating that this gradual internationalization, rather than large and spectacular foreign investments, is characteristic of the internationalization process of many international firms. It seems reasonable to believe that the same holds true for many firms from other countries with limited industrial development and competitive advantages. A related observation is that the type of development during the early stages is of importance for the following pattern. Similar observations have also been made about U.S. firms and have been used as an argument in discussions of foreign investments and international marketing. As demonstrated in the previous literature, most of the SMEs face the following challenges in their internationalization process: 1) the issues related to property rights protection, which is related to the product and technology innovation and, 2) insufficient funding sources. The SMEs may "burn out all their cash" in the internationalization process and be easily wiped out by the existing multinational companies; and 3) the barriers to entry and strive in the new markets.

We raise the following questions in this research. First of all, theoretically, what are considered as the most influential factors for international expansion of the SMEs from the developing countries, like China? What's more, what should be the policy guidelines and regulations from the China government to improve the overall rate of international diffusion of innovation by small and medium sized enterprises? Further, how did the successful shoe making entrepreneur from the 
internationalized SMEs in Wenzhou achieve their goal? Do they have something inherently different from others? Last but not the least, what can be learned from the Wenzhou shoe making case? What is the policy implication for the policy makers?

In the following sections, we will address the internationalization process first. Then the key factors on internationalization will be discussed individually, such as the domestic environmental, the entrepreneurial factor, the external resources for internationalization, the governmental support and the international environment. Then a case study on the internationalization of shoe makers in Wenzhou would provide more vivid demonstration on how the above factors work together to realize the "internationalization" dream of the local Chinese entrepreneurs.

\section{The Internationalization Process}

The phrase "international of SMEs" here is defined as either the "transformation of attitude of the SMEs towards business activities in another country" or the "actual business activities in other countries". Of course there is a close relationship between attitudes and actual behavior. The attitudes are the basis for decisions to undertake international ventures and the experiences from international activities influence these attitudes. We concentrate on the aspects of the internationalization activities which are easy to observe. We consider, however, these attitudes as interesting and important and the discussion of the internationalization process is basically an account of the interaction between attitudes and actual behavior. Most theories have been specifically presented to explain the internationalization of manufacturing firms. These theories fail to appreciate that many manufacturing as well as services firms (and entrepreneurs) do not want to export abroad. Most notably, many owner-managers do not want to commit the resources of the firm (i.e. physical, financial and managerial) to enter export markets. Further, some theories fail to appreciate that some construction and services firms (particularly, knowledge-based firms and those offering business services) have the ability and inclination to internationalize.

Traditional internationalization theory suggests that the internationally active firm can create some kind of firm-specific advantage in its domestic markets. Internationally active firms seek opportunities in foreign markets. Moreover, they seek to internationalize to reduce costs by transferring goods or services across national borders where it is cheaper to do so. By following this strategy, the firm can maintain control over the internal resources that have contributed to the firm's success in domestic markets. The ability of this perspective to explain the internationalization of small firms has been questioned and several alternative theories have been proposed.

The basic assumption of our argument is that the successful SMEs' first develop well in their domestic market and that the internationalization is the consequence of a series of incremental decision-making process and mentality transformation. We also assume that the most important obstacles to internationalization are lack of knowledge of internationalization (such as expansion, operation, legal issues, etc) and resources (such as local new contacts, cash, local distribution channel, etc). We assume that all these obstacles are well conquered through incremental decision making and evolutionary learning from the foreign markets and new business operations models. Also the entrepreneurs gradually believe that the risk of investments on internationalization decreases and the continued internationalization is stimulated by the increased need to control sales and the increased exposure to offers and demands to extend the operations. We are not trying to explain why firms start exporting but assume that, because of lack of knowledge about foreign countries and a propensity to avoid uncertainty, the firm starts exporting to neighboring countries or countries that are comparatively well-known and similar with regard to business practices etc. We also believe that the firm starts selling abroad via independent representatives, as this means a smaller resource commitment than the establishment of a sales subsidiary or establishment of a whole sales channel. Considering the development of operations in individual countries we expect a stepwise extension of operations. Of course it is possible to identify different types of steps and a different number of stages. In the previous literature, various scholars have chosen to distinguish between four different stages. They are: 1. No regular export activities; 2. Export via independent representatives (agent); 3.sales subsidiary and, 4. Production / manufacturing in other countries.

The categorization of these stages is important because they are different with regard to the degree of involvement of the firm in the market and they are often referred to by people in business.

There are two aspects about the degree of involvement. The four stages mean consequentially heavier resource commitments and they also lead to quite different business expansion experiences and information for the decision makers of the SMEs. Stage model theory of internationalization is useful when studying the internationalization of small firms that belong to conventional manufacturing industries. However, this perspective is less useful when studying the internationalization of knowledge intensive and business services firms. This perspective fails to recognize that some firms export from the outset and may generate more sales from exporting than from domestic sales. Moreover, it is increasingly recognized that new venture development is non-linear and even chaotic. Table. 1 gives a simplified stage mode of internationalization of SMEs. 
We call the sequence of stages, mentioned above, the establishment chain. We have, of course, simplified the matter somewhat by exaggerating the differences between the four steps. It is not always obvious whether a firm has established relations with an agent or not, while a joint venture with an earlier representative can be placed in the second or the third stage, etc. Of course we do not expect the development always to follow the whole chain. First, several markets are not large enough for the resource demanding stages. Second, we could expect jumps in the establishment chain in firms with extensive experience from other foreign markets. Considering the extension of activities to new markets, it is possible that the concept of psychic distance may prove useful. This concept is defined as factors preventing or disturbing the flows of information between firm and market. Examples of such factors are differences in language, culture, political systems, level of education, level of industrial development, etc. For obvious reasons, psychic distance is correlated with geographic distance. But exceptions are easy to find. Some countries in the British Commonwealth are far apart geographically, e.g. England and Australia, but for different reasons they are near to each other in terms of psychic distance. The U.S.A. and Cuba are near to each other geographically, but, for political reasons, far apart if we consider their psychic distance. As these examples indicate, psychic distance is not constant. It changes because of the development of the communication system, trade and other kinds of social exchange. In general we expect most changes to take place rather slowly. Psychic / physical distance, however, is of course not the only important factor for international operations. In most textbooks about international business the size of the potential market is considered the most important factor for international operations. The first activity phase of export planning then is identifying and measuring market opportunity. Thus we should expect that market size influences decisions in the internationalization process. We could expect either that the firm first starts operations in countries with huge potential market or that they prefer to start in smaller markets.

But there are reasons to expect that the patterns of agency establishment differ from those of sales subsidiary establishments with respect to the two factors. The agency establishments, according to the existing literatures, are made primarily during the early stages of internationalization, which means that they could be expected to be more closely related to psychic distance than to the size of the market. The sales subsidiary establishments - and still more production - could be expected to be influenced primarily by the market size as it generally requires a larger minimum resource commitment than an independent representative. The production establishments are influenced by different forces; on one hand, by psychic / physical distance, on the other, by factors such as, e.g., tariffs, non-tariff barriers and transport costs. As a result it is hard to observe any correlation between psychic distance and production establishments. A third pattern which could be expected is that after the establishment of the first agency a phase follows when agencies are established in several markets. In the same way we could expect a separate phase dominated by the establishment of sales subsidiaries in several markets. Last, a phase with the establishment of production in several markets will follow. We assume that the three different phases in the internationalization of the firm are dependent on the development of the activity knowledge and the organizational structure of the firm. During the agent phase the firm builds an export department with the capability and responsibility for the establishment and maintenance of agencies. Establishment of sales subsidiaries means that units for the control of subsidiaries are organized. In the last phase, units for coordination of production and marketing in different countries are developed. Marketing operations in this sense are important for the international activities. Furthermore it has been shown that the marketing side is often a determining factor in the development of the firm.

\section{The Influential Factors on Internationalization of the SMEs in China}

Generally, the internationalization of SMEs, especially small enterprises, can change greatly with the location of the firm in the international value chain. In the process of this change, there are several key factors that are needed to be taken into consideration. We can categorize these factors into three groups, in terms of, 1) external factors, like the global financial crisis and the changes of monetary policy, 2) the infrastructural factors, like the domestic environment context on internationalization, the governmental support and infrastructure building, and the international environment for internationalization, and 3) the congenital factors, like the entrepreneurial spirit of the SMEs, the psychic distance.

\subsection{External factors, like the global financial crisis, etc,}

Internationalization requires solid financial ability. The whole issues should be addressed under the background of a global context. Factors like the global financial crisis and changes of monetary policy should be brought into the analysis since they have a direct impact on the expansion and branding of nearly all the firms which are on their way of internationalization. For instance, the global financial crisis started in 2008 can help us reach more implications since it works a filter and leave more robust and flexible SMEs in the market so the ones who survive will have tons of opportunities behind the crisis. 
3.2The infrastructural factors, like the domestic environment context on internationalization, the governmental support and infrastructure building, and the international environment for internationalization, etc,

To defend or maintain its position in a particular business network, a firm may have to become an exporter. Firms can also be 'pulled' into becoming exporters because other firms in the same business network have established relationships with other businesses in foreign markets. Many knowledge-based business service firms reach their competitive advantage not only based on their resources (the infrastructural factors). They achieve some of their competitive advantage by developing mutually supportive interactions with other service firms and their customers. Considering the Domestic environmental context on internationalization, we would like argument that domestic environment, such as domestic market competition, domestic customer shopping attitude is one of the driving factor for the SMEs to make up an internationalization decision. External help, such the governmental support are necessary for the internationalization of any SMEs. Here the governmental support does not include the direct financing \& low interests loans and subsidies, but also the infrastructure building and maintenance. The diffusion and application of enabling technologies, such as Internet, are also factors for the internationalization of any SMEs. These technologies give the SMEs lower barriers to approach the targeted customers and finalize the deal.

\subsection{The congenital factors like the entrepreneurial spirit of the SMEs and the psychic distance.}

The decision of entrepreneurs to export their goods and pursue a strategy of internationalization can be influenced by internal and external environmental conditions and stimuli. However, different entrepreneurs may have different competencies and skills from other individuals in the general population. This difference of knowledge is the key differentiator that enables entrepreneurs to make judgments, co-ordinate scarce resources and make strategic decisions which involve the reallocation or organization of their businesses resources based on the information they have acquired. Awareness of market imperfections requires knowledge about market factors, information about market opportunities, insights into customer needs as well as the ability to deliver the products or services required by customers or take certain risks. Also the statistics shows that the entrepreneurs that with a closer psychic distance to their targeted market are more easily to internationalize their company so this factor should also taken into consideration for analysis.

\section{Facts on Internationalization of the Wenzhou Shoemaking SMEs}

The global map of industrial production is in a state of nearly unprecedented flux, reflecting China's spectacular rise in the last few years and success in becoming a dominant manufacturer in the world economic arena. Although still be considered as a centralized \& government controlled state, the country's most dramatic growth in output has occurred in exportable consumer goods such as clothing and footwear, and Wenzhou's SMEs are the pilots in this sector. Exports from China have flooded over the International markets, so that the country has by now earned the well-deserved reputation as the "world's factory." In 2008, its GDP became the world's third-largest, surpassing that of Germany and challenging the leading position of the United States. How has China achieved its remarkable rise in production, and what roles have its industries and regions played in the process? The country's footwear industry represents a clear example of China's rise in manufacturing, and thus provides some revealing answers to that question. The limited Western literature posits that China's footwear factories are concentrated in the export-oriented Pearl River Delta (PRD), where growth is driven by foreign investment and external production under a blueprint for development popularly known as the PRD model (e.g., see Scott, 2006). But while this picture reflects the situation in the early 1990s, it needs to be updated, if for no other reason that several major centers of footwear production including Quanzhou (Fujian Province), Chengdu (Sichuan), and Chongqing and Wenzhou (Zhejiang) also have by now been established in China.

\subsection{Background introduction on Wenzhou}

Wenzhou, as shown in Fig.1, was a prosperous foreign treaty port, which remains well-preserved today. It is situated in a mountainous region and, as a result, has been isolated for most of its history from the rest of the country, making the local culture and language very different from those of neighboring areas. It is also known for its emigrants who leave their native land for Europe and the United States, with a reputation for being enterprising natives who start restaurants, retail and wholesale businesses in their adopted countries.

The shoe industry is one of the traditional and leading industries in Wenzhou, with a history spanning over half a millennium and responding to the dramatic growth in tandem with China's economic reforms of the late 1970s. A cluster containing nationally significant enterprises has emerged in Wenzhou, where most shoe-making components can be obtained locally. The industry has scaled-up both nationally and internationally, expanding sales networks and factories across China and abroad. Spatial expansion has entailed dispersion of production to interior China, with the goal of lowering costs, and diversification of firm activities. In the process, Wenzhou itself has changed. The orthodox notions of locally based industrial districts and clusters no longer capture the essence of the new Wenzhou model. The 
experience of the footwear industry once again indicates that successful industrial districts have the ability to adapt to change, challenging the New Regionalism literature that unduly emphasizes the role of small firms as well as of local assets and institutions. Wenzhou's entrepreneurs are also on their way to strategic coupling with leading global firms and integration with global networks.

\subsection{The domestic environment context on internationalization}

The intensive shoe manufacturing competition in China, or the domestic environment, is another influential factor for the Internationalization of Wenzhou shoe SMEs. Though the international consumers have been spending more and more respect for the natural process, the pursuit of health and comfort while in the pursuit of life, they often are in the shoes of "green" on the consideration of this company is qualified, if the shoe is simple to consumers to provide innovative products and neglect the appearance of the green, the survival time of such enterprises is usually not long. Because in the China, social, environmental conflicts exist, do not pay attention to environmental protection, resource conservation, and many other factors, it is difficult to achieve sustainable consumption. The major deterministic factor of buying shoes are the price and majority of the people do not care much about the brand and manufacturer, so the Wenzhou shoe SMEs are forced to differentiate from their Chinese counterparts. They are carrying out the operation process of green ideas, minimizing consumption of resources, for resources recycling and building an up greener enterprise image. Thus the domestic environment context or competition is another important factor for the internationalization of Wenzhou SMEs.

\subsection{The entrepreneurial spirit of Wenzhou Businessman}

Due to Wenzhou's cultural and geographical remoteness and its lack of natural resources (land, minerals, etc.), the Chinese central government has left the people of Wenzhou relatively autonomous. Away from the center of the political and economic stage, its people are more independent, self-reliant, and generally more business-oriented. Numerous books have been published about the business sense of people from Wenzhou. Hence, when China switched from its planned economy to its so-called capitalist economy with Chinese (socialist) characteristics in the late 1980s, its people adjusted well to the new system and took advantage of it. A popular saying calls Wenzhou businessmen the "Jews of the Orient". Wenzhou businessmen have been stereotyped by other Chinese as real estate speculators. China Daily notes that investments from Wenzhou businessmen buyers play a disproportionately large role in the increase in Chinese property prices. The people of Wenzhou are equipped with business sense and a commercial culture more dominant than anywhere else in China. Wenzhou has two economic characteristics: it was the first to launch a market economy, and it has the most active and developed private economy in China. In the process of developing its economy, its people have survived adversity, with little positive help from the government.

We believe this is the most inevitable factor for the internationalization of Wenzhou Shoe SMEs. Vitality comes from Wenzhou natives. Without much dependence in state investments, the development of the city lies on the efforts of the native population. Vitality results from business culture, which is the top feature of Wenzhou's economy. Wenzhou businessmen have set their feet on the way of accumulating capital and also made themselves one of the important forces of the overseas Chinese businessmen. "Big market with small commodities, small money with high capital intensity" has become the prominent character of Wenzhou's economy. As mentioned above, there are many Wenzhou businessmen in US and Europe and they have adapted the life there and started solid business.

\subsection{The governmental support and infrastructure building}

From the perspective of governmental support, we can find that the direct financing as well as the infrastructure building by the Wenzhou local government and China central government are the critical factors for the Internationalization of Wenzhou shoe SMEs. For example, Wenzhou Economic \& Technological Development Zone was established and approved by State Council in 1992. The main traffic system around the zone includes No.104 National Highway, Ningbo-Wenzhou Expressway and Wenzhou Bridge. It is located near to Wenzhou International Airport and Wenzhou Port. Industries encouraged in the zone include electrical equipment, electronic information, chemical medicine, building materials, and textiles. On the infrastructure side, the Wenzhou Yongqiang Airport serves the Wenzhou area, with scheduled flights to major cities in mainland China as well as Hong Kong and Macau. Air route to Hong Kong was open in 1996. Linking 65 cities in the country with 34 permanently operating air routes, the Airport is among the fastest-growing and profitable among its peers in China. Having been cut off from rail transport for much of its history, CRH (China Railway High-speed) trains have began operation in Wenzhou as of September 2009, linking the city with Hangzhou and Ningbo in the north, and Fujian province in the South, transforming Wenzhou from a terminal of rail way network into an important inter-change Delta and West Strait region. The Wenzhou shoe SMEs has a much bigger chance to spin-off with the infrastructure and governmental support. 


\subsection{The international environment for internationalization}

Back to 10 years ago, the majority of the studies of ICT by Wenzhou SMEs have focused on the traditional internet with little attention paid to the emerging Search Engines Optimizations. The traditional internet as a communication medium can be characterized by three significant disadvantages - it is generally asynchronous, it lacks place, slow in speed, and it is descriptive rather than experiential. However, recent advances in bandwidth and network connectivity have led to the rapid development of this virtual world. This virtual world generates a virtual market and arena for the Wenzhou SMEs. In a recent search carried out by a leading portal in China, nearly $90 \%$ of the entrepreneurs from shoe manufacturing SMEs in Wenzhou are paying more and more attention on Internet-based business and marketing strategies. This virtual world can provide a medium for SMEs to acquire foreign market knowledge to facilitate their internationalization process. Nearly $83 \%$ of them have a clear idea of Search Engine Optimization (SEO) and 53\% attempted or outsourced the Search Engine Optimization to the 3rd party technology companies. From this prospective, the internet enables the SMEs some alternatives, including the relatively cost-low marketing channel, online-branding and direct sales to the foreign the market.

\subsection{The global financial crisis}

China and Wenzhou now confront a new round of economic challenges posed by the problem of declining exports inflicted by the global economic recession. Like most other manufacturing sectors, the footwear industry in Wenzhou experienced a difficult environment in early 2009. During the first half of that year, its output declined by 8.1 percent. Wenzhou may thus need to revise the old reform blueprints to again modify its local institutions and improve its economy in tandem with the footwear industry. Concrete steps in this direction were taken in 2009, as part of the research and design work on the municipality's Ninth Five-Year plan. While the obstacles appear to be daunting, the region's internal dynamics and capabilities may yet enable it to meet the new challenges. During the global financial crisis, many SMEs stopped producing because of the sharp decrease in overseas orders. Up to 20 percent of these companies reportedly shut down. But Wenzhou's shoe exports are getting back on track in the economic recovery. The city's export volume in the first 10 months of 2010 reached $\$ 11.7$ billion ( 8.78 billion euros), according to the last data, 32.4 percent more than the total volume in 2009. More than 40 percent of the products were shipped to European countries, making the European market the biggest target of Wenzhou's international trade, according to the Wenzhou foreign trade and economic cooperation bureau. The Wenzhou Evening News reported in September that about 120 Wenzhou shoes enterprises contribute more than 80 percent of the market in France, two decades after they entered the European market. The shoe sector contributed about $\$ 3.1$ billion to the economy, \$ 350 million more than last year's. Exports of clothes hit $\$ 1.21$ billion this year, up by 18.5 percent from 2009. From this perspective, conclusion can be reached that though the financial crisis hits the shoe business in Wenzhou; the Wenzhou SMEs are more resilient to this sudden change and building up a more solid sales network.

\section{Conclusions and Implication}

This paper has attempted to develop both conceptual understanding of the Internationalization of SMEs and case analysis relating to the shoe making SMEs in Wenzhou. In terms of conceptual development, this paper has presented a critical evaluation of stage model theory of internationalization. A resource-based perspective has been presented that emphasizes the key role of resource constraints with respect to whether small firms export and the mode of exporting that was adopted. Several weaknesses of this study need to be noted. First, the case study of the Wenzhou shoe making industry is relatively qualitative. Second, both the samples had inevitably suffered from the problem of data issues. The data used in the study is related old, especially after the global financial crisis, the SMEs and internationalization data should varies a lot. As a result, evidence from the follow-on samples does not provide a comprehensive picture of the export behavior of all SMEs in Wenzhou and China.

Policy-makers and practitioners could consider introducing initiatives that target resources and assistance to the relatively smaller proportion of owner-managed firms that have the inclination as well as the ability to be exporters. The targets of the support should be the firms that have solid entrepreneurial skills and long term business plan. Moreover, rather than encouraging all of the small firms to become exporters, policy-makers wanting to maximize returns on investments could, therefore, consider targeting their scarce resources to existing exporters. Exporting firms are relatively easy to identify. Existing exporters already appreciate the benefits as well as the problems associated with selling goods or services abroad. Besides, the policy-makers should pay attention to the domestic market and help the SMEs to cultivate their customers and market since the brand-shoe market potential in China is much higher than any existing and mature foreign markets.

Future research might usefully be focused on four main aspects. First, studies should increasingly consider the internationalization strategies of services as well as manufacturing firms. Theories explaining the internationalization of 
manufacturing and construction / services firms should consider the wide range of demand and supply-side factors which influence business internationalization. Studies should explore whether the approach to internationalization differs between industries (i.e. finer level studies focusing upon standard industrial categories), whether the approach to internationalization differs depending upon the environmental context (i.e. rural or urban) of a business's main operational premises and the types of businesses in terms of their resource endowments (including the entrepreneur) and their ability to acquire resources.

Second, additional careful longitudinal research is still required. This might usefully focus upon the internationalization of 'micro', 'small' and 'medium' sized firms engaged in a variety of industrial activities rather than studies focusing solely upon large manufacturing firms. Additionally, this research could chart the lifecycle of small firms' internationalization processes and identify the critical factors required for successful internationalization. Longitudinal studies are required to evaluate alternative causal processes and changing influences on foreign-country market selection and entry mode choice. Qualitative research approaches may be particularly useful in this respect. Last but not the least, future studies relating to the above issues could usefully utilize quantitative as well as qualitative methodologies used in this article in order to identify the key factors encouraging firms to internationalize. In particular, the inevitable sample attrition problem highlighted in this study suggests there is a need to replicate this study using large representative samples of manufacturing in Wenzhou and other key cities in China.

\section{References}

Ahlstrom, D., Bruton, G., \& Yeh, K. (2007). Venture capital in China: Past, present, and future. Asia Pacific Journal of Management, 24(3), 247-268. doi:10.1007/s10490-006-9032-1, http://dx.doi.org/10.1007/s10490-006-9032-1

Ahlstrom, D., Young, M.N., Chan, E.S., \& Bruton, G.D. (2004). Facing constraints to growth? Overseas Chinese entrepreneurs and traditional business practices in East Asia. Asia Pacific Journal of Management, 21(3), 263-285. doi:10.1023/B:APJM.0000036463.20310.de, http://dx.doi.org/10.1023/B:APJM.0000036463.20310.de

Aldrich, H. \& Fiol, C. (1994). Fools rush in? The institutional context of industry creation. Academy of Management Review, 19, 645-670. doi:10.2307/258740, http://dx.doi.org/10.2307/258740

Alvarez, S. \& Busenitz, L.W. (2001). The entrepreneurship of resource-based theory. Journal of Management, 27, 755-775. doi:10.1177/014920630102700609, http://dx.doi.org/10.1177/014920630102700609

Asher, S.K. \& Mehta, S. (2004). New regulations and landmark ruling clarify investment tax. International Financial Law Review, 19-21.

Barney, J. (1991). Firm resources and sustained competitive advantage. Journal of Management, 17, 99-120. doi:10.1177/014920639101700108, http://dx.doi.org/10.1177/014920639101700108

Autio, E., Sapienza, H.J., \& Almeida, J. (2000). Effects of age at entry, knowledge intensity, and imitability on international growth. Academy of Management Journal, 43, 909-924. doi:10.2307/1556419, http://dx.doi.org/10.2307/1556419

Baker, T., Gedajlovic, E., \& Lubatkin, M. (2005). A framework for comparing entrepreneurship processes across nations. Journal of International Business Studies, 36, 492-504. doi:10.1057/palgrave.jibs.8400153, http://dx.doi.org/10.1057/palgrave.jibs.8400153

Bell, R.G., Moore, C.B., \& Al-Shammari, H.A. (2007). Country of origin and foreign IPO legitimacy: Understanding the role of geographic scope and insider ownership. Working paper presented at the Entrepreneurship Theory and Practice Conference at Texas Christian University.

Brouthers, L.E., O'Donnell, E., \& Hadjimarcou, J. (2005). Generic product strategies for emerging market exports into Triad nation markets: A mimetic isomorphism approach. Journal of Management Studies, 42, 225-245. doi:10.1111/j.1467-6486.2005.00495.x, http://dx.doi.org/10.1111/j.1467-6486.2005.00495.x

Hitt, M.A., Ireland, D., Camp, M., \& Sexton, D. (2001). Entrepreneurial strategies for wealth creation. Strategic Management Journal, 22, 479-491. doi:10.1002/smj.196, http://dx.doi.org/10.1002/smj.196

Hoskisson, R.E., Eden, L., Lau, C.M., \& Wright, M. (2000). Strategy in emerging economies. Academy of Management Journal, 43, 249-267. doi:10.2307/1556394, http://dx.doi.org/10.2307/1556394

Jones, M. \& Coviello, N.E. (2005). Internationalization: Conceptualizing an entrepreneurial process of behavior in time. Journal of International Business Studies, 36, 284-303. doi:10.1057/palgrave.jibs.8400138, http://dx.doi.org/10.1057/palgrave.jibs.8400138 
Knight, G.A. (2001). Entrepreneurship and strategy in the international SME. Journal of International Management, 7, 155-171. doi:10.1016/S1075-4253(01)00042-4, http://dx.doi.org/10.1016/S1075-4253(01)00042-4

Lu, Y. (2007). Home-based product strategies and export performance in international entrepreneurial firms. Working paper, Chinese University of Hong Kong.

Lumpkin, G.T. \& Dess, G. (1996). Clarifying the entrepreneurial orientation construct and linking it to performance. Academy of Management Review, 21(1), 135-172. doi:10.2307/258632, http://dx.doi.org/10.2307/258632

Luo, Y. \& Mezias, J.M. (2002). Liabilities of foreignness: Concepts, constructs, and consequences. Journal of International Management, 8(3), 217-221. doi:10.1016/S1075-4253(02)00066-2, http://dx.doi.org/10.1016/S1075-4253(02)00066-2

Mike Wright; Paul Westhead; Deniz Ucbasaran, The Internationalization of SMEs and International, Journal on Regional Studies, Volume 41, Issue 7 October 2007 , pages 1013 - 1030. doi:10.1080/00343400601120288, http://dx.doi.org/10.1080/00343400601120288

Maria Holmlund, Sören Kock and Vladimir Vanyushyn, Small and Medium-sized Enterprises' Internationalization and the Influence of Importing on Exporting, International Small Business Journal 2007; 25; 459, doi:10.1177/0266242607080655, http://dx.doi.org/10.1177/0266242607080655

Peng, M.W. \& Wang, D. (2000). Innovation capability and foreign direct investment: Toward a learning option perspective. Management International. Review, 40, 79-93.

Peng, M.W. \& Zhou, J.Q. (2005). How network strategies and institutional transitions evolve in Asia. Asia Pacific Journal of Management, 22, 321-336. doi:10.1007/s10490-005-4113-0, http://dx.doi.org/10.1007/s10490-005-4113-0

Peng, M.W. (2006). Global strategy. Cincinnati, OH: Thomson South-Western.

Peng, M.W. (2007). Celebrating 25 years of Asia Pacific management research. Asia Pacific Journal of Management, 24(4), 385-393. doi:10.1007/s10490-007-9059-y, http://dx.doi.org/10.1007/s10490-007-9059-y

Sapienza, H., Autio, E., George, G., \& Zahra, S. (2006). A capabilities perspective on the effects of early internationalization on firm survival and growth. Academy of Management Review, 31, 914-933.

Scheela, W.J. \& Van Dinh, N. (2004). Venture capital in a transition economy: The case of Vietnam. Venture Capital, 6(4), 333-350. doi:10.1080/1369106042000258508, http://dx.doi.org/10.1080/1369106042000258508

Scott, W.R. (1995). Institutions and Organizations. Thousand Oaks, CA: Sage.

Shane, S. \& Venkataraman, S. (2000). The promise of entrepreneurship as a field of research. Academy of Management Review, 25(1), 217-226. doi:10.2307/259271, http://dx.doi.org/10.2307/259271

Zoltan J. Acs, Randall Morck, J. Myles Shaver and Bernard Yeung, The Internationalization of Small and Medium-Sized Enterprises: A Policy Perspective. SMALL BUSINESS ECONOMICS, Volume 9, Number 1, 7-20, doi: 10.1023/A:1007991428526, http://dx.doi.org/10.1023/A:1007991428526 
Table 1. The categorization of different phases of the internationalization

\begin{tabular}{|c|l|}
\hline Phases & \multicolumn{1}{|c|}{ Implications } \\
\hline $\begin{array}{c}\text { No regular export } \\
\text { activities }\end{array}$ & $\begin{array}{l}\text { Indicates that the SMEs have no commitment of } \\
\text { resources and time to the market abroad and that they } \\
\text { do not have any appropriate information channel to } \\
\text { reach the market and derive knowledge from the market } \\
\text { abroad. }\end{array}$ \\
\hline $\begin{array}{c}\text { Export via independent } \\
\text { representatives (agent) }\end{array}$ & $\begin{array}{l}\text { Means that the firm has a channel to the market through } \\
\text { which it gets fairly regular information about sales } \\
\text { influencing factors. It also means a certain commitment } \\
\text { to the market. }\end{array}$ \\
\hline $\begin{array}{c}\text { Sales subsidiary / } \\
\text { branches }\end{array}$ & $\begin{array}{l}\text { Has a controlled information channel to the market, } \\
\text { giving the firm ability to direct the type and amount of } \\
\text { information flowing from the market to the firm. } \\
\text { During this stage the firm also gets direct experience of } \\
\text { resource influencing factors. }\end{array}$ \\
\hline $\begin{array}{c}\text { Design / Production / } \\
\text { manufacturing in other } \\
\text { countries }\end{array}$ & $\begin{array}{l}\text { Means a growing control of the international subsidiary } \\
\text { and constant and large resource and time commitment }\end{array}$ \\
\hline
\end{tabular}

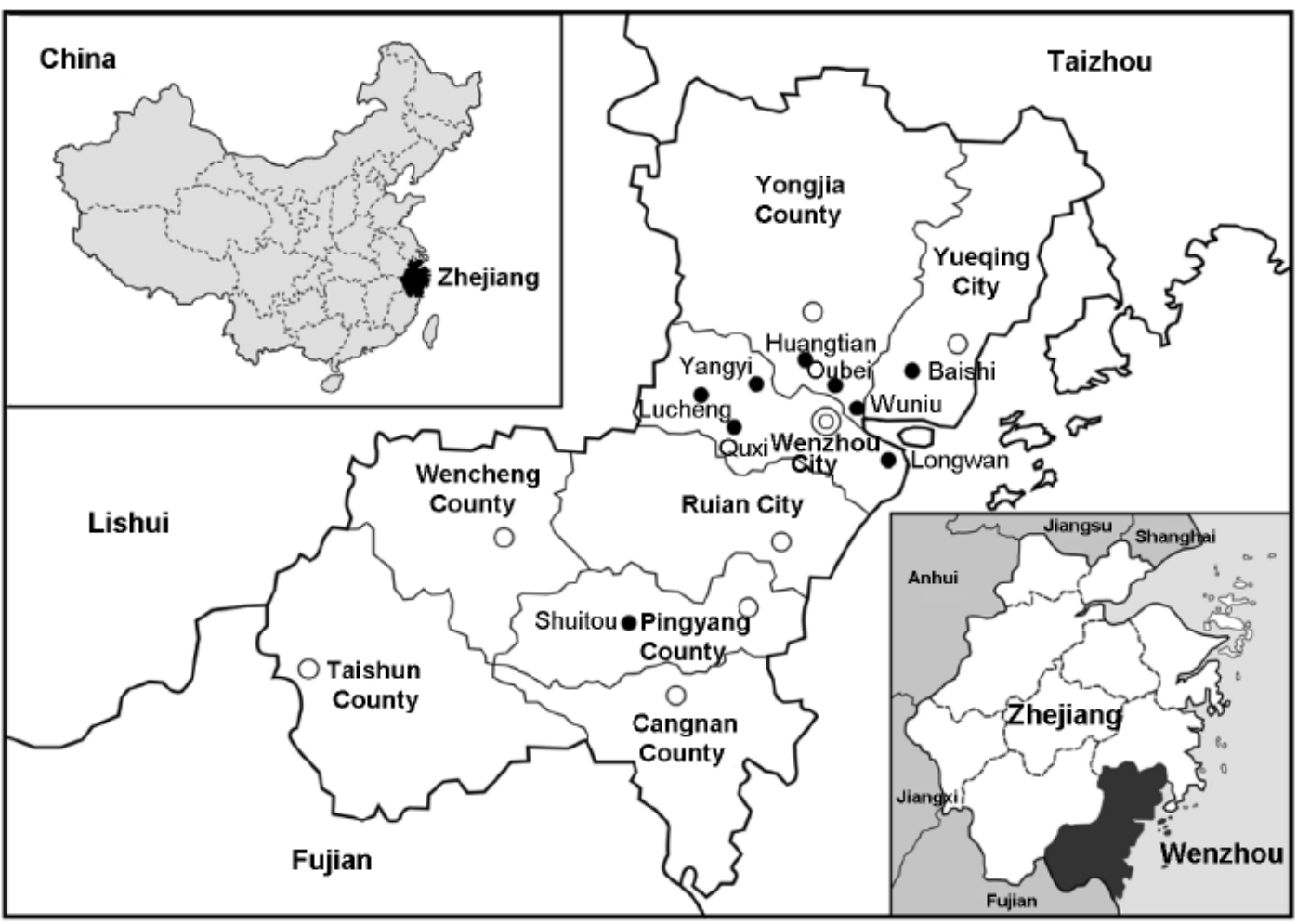

Figure 1. General location of Wenzhou Municipality and sites of footwear production. 


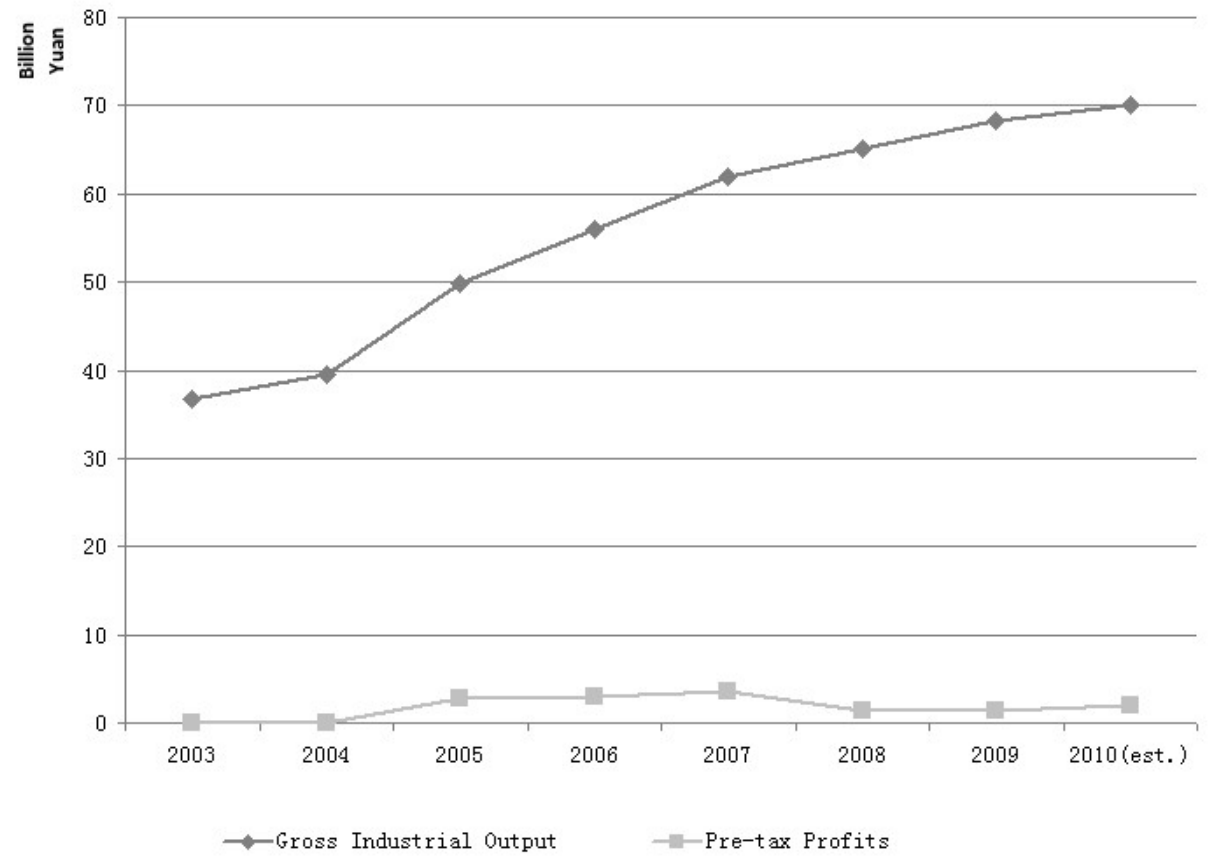

Figure 2. Value of output and pre-tax profits of Wenzhou's footwear industry 2003-2010 (est.), in current yuan 